\title{
Development of the knowledge of fertility and fertility preservation scale
}

This article was published in the following Dove Press journal:

Nursing: Research and Reviews

12 April 2012

Number of times this article has been viewed

\author{
Angela Jukkala' \\ Karen Meneses' \\ Andres Azuero' \\ June Cho' \\ Patrick McNees ${ }^{1,2}$ \\ 'School of Nursing, ${ }^{2}$ School of Health \\ Professions, University of Alabama at \\ Birmingham, Birmingham, AL, USA
}

Objective: Infertility is a severe and often underestimated consequence of successful treatment for breast cancer. Ensuring young breast cancer survivors receive patient-centered health information on the impact of treatment on fertility and fertility preservation options in a timely manner is a critical component of high quality nursing care. The objective of this manuscript is to report the process used to develop and examine the reliability and validity of an instrument to measure a breast cancer survivor's self-assessed knowledge of fertility and fertility preservation.

Design: A scale development and descriptive study.

Setting: Online and global.

Participants: Ninety-two young breast cancer survivors (ages 25-45 years).

Methods: Participants completed the Knowledge of Fertility and Fertility Preservation (KF) Scale as part of their participation in a larger study, the Fertility Cancer Project (FCP).

Results: An exploratory factor analysis revealed five domains: normal reproductive function; general information about fertility; cancer treatment factors affecting fertility; infertility information; and alternative parenting options. A confirmatory factor analysis confirmed the validity of the construct with a demonstrated good fit between the factor structure of the new scale and the observed data. Many participants self-assessed their overall knowledge of fertility and fertility preservation as "a little" and the majority rated their knowledge of infertility information as "a little".

Conclusion: The KF Scale can be used to provide useful information to support health care professionals in the development of patient-centered education that is responsive to the unique needs of each young breast cancer survivor. The initial testing of the KF Scale indicates that it is reliable and easy to use; however, additional testing with larger and more diverse groups of breast cancer survivors is needed to further determine reliability and validity. The KF Scale could also be examined as a possible measure of self-assessed knowledge of fertility and fertility preservation across diverse groups of young cancer survivors, such as survivors of Hodgkin's disease or childhood leukemia.

Keywords: knowledge of fertility, knowledge of fertility and fertility preservation scale, Fertility Cancer Project

\section{Introduction}

Each year, 25,000 premenopausal, fertile women ( $<50$ years of age) are diagnosed with breast cancer. ${ }^{1}$ While early diagnosis and advances in treatment have greatly increased the likelihood of long-term survival, the same lifesaving treatment often has profound negative effects on future fertility. ${ }^{2}$ The incidence of ovarian failure post-treatment and subsequent infertility increases dramatically with age, for example approximately $10 \%-20 \%$ of women aged under 35 years will experience infertility
Correspondence: Angela M Jukkala

School of Nursing, University of Alabama at Birmingham, 312 School of Nursing

Building, I70I University Boulevard

Birmingham, AL 35294, USA

Tel +l 2059966 |36

Email jukkalaa@uab.edu submit your manuscript | www.dovepress.com

Dovepress

http://dx.doi.org/1 0.2/47/NRR.S28248
Nursing: Research and Reviews 2012:2 I-7

(C) 2012 Jukkala et al, publisher and licensee Dove Medical Press Ltd. This is an Open Access article which permits unrestricted noncommercial use, provided the original work is properly cited. 
compared to $90 \%$ of women aged 40 years and older. ${ }^{3-5}$ As more and more women delay childbearing until later in life, it is likely that many will not have fulfilled childbearing goals. The desire to maintain the ability to bear a biological child is a critical quality-of-life concern for the majority of young cancer survivors regardless of the extent of their disease. ${ }^{6}$ Individuals dealing with infertility report experiencing stress levels that are comparable to those of a person dealing with a diagnosis of cancer or acquired immunodeficiency syndrome. ${ }^{7}$ Immediately following diagnosis, young breast cancer survivors are likely to be overwhelmed with the diagnosis of breast cancer and the subsequent threat to future childbearing as well.

The ideal time for effective fertility preservation is prior to initiating chemotherapy. ${ }^{8,9}$ The current standard and most widely used method of fertility preservation is in-vitro fertilization with cryopreservation of the resulting embryos for implantation once treatment for cancer is complete. ${ }^{10}$ However, this method requires women to delay chemotherapy for several weeks to stimulate the ovaries and gather and fertilize oocytes for cryopreservation. Thus, young breast cancer survivors must be able to access, interpret, and act upon complex health information in a relatively short period of time. Unfortunately, multiple studies have shown that most young cancer survivors do not receive the information they need to support informed medical decision making for fertility preservation. ${ }^{11-13}$ Nurses need to be able to provide patient-centered health information specific to meet an individual breast cancer survivor's needs across the entire spectrum of survivorship, including possible infertility and fertility preservation.

The Fertility and Cancer Project (FCP) was a dedicated research project focused on electronically delivering reproductive health and fertility education. The integration of electronically delivered health information, description of the FCP development, ${ }^{14}$ and preliminary analysis of the efficacy of the $\mathrm{FCP}^{15}$ are described in detail elsewhere. During the development of the FCP, investigators found no available instruments to support the self-assessment of knowledge of fertility and fertility preservation among young breast cancer survivors. Self-reporting scales, such as the Knowledge of Fertility (KF) Scale, are developed in response to a specific need, absence, and/or lack of suitable measure available or intended for a specific research project. ${ }^{16}$

Guidelines from the Institute of Medicine ${ }^{17}$ advocate for patient-centered health education based on each patient's individual needs and preferences. While self-assessment of knowledge is a methodology commonly used among health care professions to allow for reflection of knowledge levels and to guide educational activities, ${ }^{18-20}$ little is known about the use or efficacy of educational self-assessment within an oncology patient population. Valid and reliable instruments to support self-assessment of knowledge strengths and weaknesses will allow health care professionals to develop and deliver patient-centered educational interventions of both needed and desired health information in a timely manner.

The KF Scale was developed to measure breast cancer survivors' self-assessed level of knowledge of the reproductive cycle, general health factors that may affect fertility, the effect of breast cancer treatment on fertility, treatment of infertility, and alternative parenting options. The purpose of this paper is to describe: (a) development of the KF Scale; (b) preliminary evaluation of the KF Scale items; (c) clinical implications of the KF Scale; and (d) explore potential future testing and expansion of the KF Scale.

\section{Development of the KF Scale}

The content of the KF Scale was developed through a comprehensive review of the literature, researcher clinical expertise, and expert review to meet the fertility and fertility preservation knowledge needs of young breast cancer survivors. The initial version of the KF Scale included 13 content areas grouped into three subscales:

- Treatment Factors Affecting Fertility: Comprised six items to examine self-assessed knowledge of breast cancer, chemotherapy, radiation therapy, hormonal therapy, pregnancy and breast cancer, and children after cancer.

- Infertility Information: Comprised three items to examine self-assessed knowledge of infertility "work up", assisted reproductive technology, and egg, embryo, and sperm donation.

- Alternative Parenting Options: Comprised four items to examine self-assessed knowledge of psychosocial concerns, surrogacy and gestational carriers, adoption, and child-free living.

All items were scored on a 1-3 rating scale with 1 representing "a little", 2 representing "some", and 3 representing "a lot" of knowledge.

Prior to pilot testing, the KF Scale was reviewed for content, readability, and clarity by two registered nurses with clinical experience caring for breast cancer survivors and an individual who had experienced infertility (no personal history of cancer). Each reviewer was provided with a paper copy of the KF Scale and instructed to review carefully for content, readability, and clarity and then to return 
the KF Scale with any written comments to the researchers. This review indicated that the KF Scale failed to take into consideration survivor knowledge of basic reproductive physiology, endocrine function, and general health conditions, though they are fundamental to fully understanding assisted reproductive technology. Thus, the KF Scale was revised to include two additional subscales:

- Normal Reproductive Function: comprised four items to examine self-assessed knowledge of the female reproductive cycle, follicular phase, ovulatory phase, and luteal phase.

- General Information about Fertility: comprised four items to examine self-assessed knowledge of the impact of age, obesity, smoking, and chronic health problems on fertility.

Items on the KF Scale now totaled 21.

Presentation of the progress in the development of the FCP at the 2004 Komen for the Cure Mission Conference ${ }^{21}$ provided the opportunity to further examine the content, readability and clarity of the KF Scale. Informal feedback from attendees at the FCP poster session indicated that the KF Scale was easy to understand. However, many attendees identified the ability to access high quality health information on the internet as an essential skill. Based on this feedback, a final item, online resources, was added to the Infertility Information subscale to examine self-assessed knowledge of using the internet to gather health information on fertility and fertility preservation. The final version of the KF Scale contains five subscales with 22 items.

\section{Methods}

\section{Procedure}

Following Institutional Review Board approval, a combination of traditional and electronic recruitment methods were utilized to recruit participants. A one-page announcement containing information about the purpose of the FCP and registration process was distributed at a national oncology meeting. This announcement was also distributed electronically through an advocacy group Website, the FCP homepage, and as an email to over 200 oncology health care professionals. Participants completed the KF Scale as part of the larger online FCP study conducted between 2004 and 2005. Eligibility criteria included: $18-50$ years of age, personal history of breast cancer, English speaking, and having Internet access. Following the provision of electronic informed consent, participants entered the FCP study and were issued a user identification and password. After completing self-report baseline measures (including the KF Scale), participants could self-navigate through the online educational intervention at their own pace.

\section{Data analysis}

Participants' responses to each of the 22 KF Scale items were tabulated. An exploratory factor analysis was conducted to examine construct validity. Based on the results of the factor analysis, several items were moved to different subscales (Table 1) from those initially assigned. Internal consistency, as measured by Cronbach's alpha coefficient, was estimated using the entire instrument, as well as separately for each of the five subscales. A total scale score was calculated by averaging the scores from all items. Subscale scores were computed by averaging the scores of items contained within each subscale. Corrected item-total correlations were computed between each item and the total scale, and between each item and its respective subscale. For computation of a corrected item-total correlation, the item under consideration is removed from the calculation of the total score.

In order to examine criterion-related validity, the total and subscale scores were tested for association with three items from separate study questionnaires: (1) treatment status (had not started treatment/currently receiving treatment/treatment completed); (2) consultation with reproductive endocrinologists (yes/no); and (3) educational background (less than college education/college graduate/graduate school). The criteria tested were: (1) participants who had completed treatment should have been exposed to health information on fertility and fertility preservation prior to initiating treatment and therefore should obtain higher scores; (2) participants who have had consultations with reproductive specialists should have been exposed to more information on fertility and fertility preservation and therefore should obtain higher scores; and (3) participants with higher levels of education should obtain higher scores. General linear models were used to conduct the association tests. For all criterion-related tests, the significance level was held at the traditional 0.05 level.

\section{Results \\ Sample}

The initial testing of the KF Scale was with 96 FCP participants who completed the instrument at baseline. FCP participant mean age was 34.3 years (standard deviation [SD] $=4.38$; range: $25-45$ years). The majority were Caucasian $(n=87 ; 90 \%)$, and had a college education $(n=89$; 93\%). Most were working either full- or part-time $(\mathrm{n}=76$; $79 \%)$ and about two-thirds $(n=67 ; 69 \%)$ reported family incomes greater than USD\$50,000. Participants learned of 
Table I Principal factor analysis oblimin-rotated factor pattern $(n=96)$

\begin{tabular}{|c|c|c|c|c|c|}
\hline KF subscale or item & Factor I & Factor 2 & Factor 3 & Factor 4 & Factor 5 \\
\hline \multicolumn{6}{|l|}{ Normal Reproductive Function } \\
\hline Female reproductive cycle & 0.54 & & & & \\
\hline Follicular phase & 0.85 & & & & \\
\hline Ovulatory phase & 0.77 & & & & \\
\hline Luteal phase & 0.72 & & & & \\
\hline \multicolumn{6}{|l|}{ General Information about Fertility } \\
\hline Age & & 0.38 & 0.28 & & \\
\hline Obesity & & 0.64 & & & \\
\hline Smoking & & 0.75 & & & \\
\hline Chronic health problems & & 0.54 & & & \\
\hline \multicolumn{6}{|l|}{ Treatment Factors Affecting Fertility } \\
\hline Breast cancer & & & 0.87 & & \\
\hline Chemotherapy & & & 0.75 & & \\
\hline Radiation therapy & & & 0.66 & & \\
\hline Hormonal therapy & & & 0.41 & & \\
\hline \multicolumn{6}{|l|}{ Infertility Information } \\
\hline Assisted reproductive technology & & & & 0.73 & \\
\hline Egg, embryo, and sperm donation & & & & 0.85 & \\
\hline Infertility workup & 0.29 & & & 0.49 & \\
\hline Psychosocial concerns ${ }^{\mathrm{a}}$ & & & & 0.41 & \\
\hline Child-free living $^{\mathrm{a}}$ & & & & 0.28 & \\
\hline Online resources & & & & 0.34 & 0.28 \\
\hline \multicolumn{6}{|l|}{ Alternative Parenting Options } \\
\hline Pregnancy and breast cancer ${ }^{\mathrm{b}}$ & & & & & 0.69 \\
\hline Children after cancer ${ }^{\mathrm{b}}$ & & & & & 0.81 \\
\hline Surrogacy and gestational carriers & & 0.29 & & 0.36 & 0.34 \\
\hline Adoption & & & & & 0.62 \\
\hline
\end{tabular}

Notes: Only loadings of absolute value greater than or equal to 0.28 are shown. altem was originally included in the Alternative Parenting Options subscale; bitem was originally included in the Factors Affecting Fertility subscale.

Abbreviation: KF, Knowledge of Fertility.

the FCP mainly through advocacy groups $(n=68 ; 70 \%)$ and Web searches $(n=10 ; 10 \%)$.

\section{KF Scale reliability and validity}

No missing responses were detected among the 96 participants whose responses were used to test the KF Scale. A principal-factor oblimin-rotated exploratory factor analysis using squared multiple correlations as initial communality estimates and constrained to explain at least $95 \%$ of the estimated common variance resulted in five factors, of which the first four had eigenvalues $\geq 1$, and the fifth had an eigenvalue estimated at 0.87 . The five factors were retained, as five subscales had been initially designed for the scale. Interfactor correlations ranged from 0.14 to 0.44 . Factor loadings and final assignment of items to their respective subscales are presented in Table 1. Totals and percentages of responses for items, average scale and subscales scores, corrected correlations between items and total scale, and between items and subscales are presented in Table 2. Internal consistency was adequate in the FCP sample. Cronbach's alpha for the entire instrument was estimated at 0.91. Cronbach's alpha coefficients for the Normal Reproductive Function, General Information about Fertility, Treatment Factors Affecting Fertility, Infertility Information, and Alternative Parenting Options subscales were estimated at $0.85,0.73,0.80,0.80$, and 0.78 , respectively. Subscale items that participants reported knowing the least about were "surrogacy and gestational carriers" ("a little", $\mathrm{n}=78 ; 81.3 \%$ ), "luteal phase" ("a little", $\mathrm{n}=70$; $72.9 \%$ ) and "infertility work-up" ("a little", $\mathrm{n}=67 ; 69.8 \%$ ). Subscale items participants reported knowing the most about were "smoking" ("a lot", $n=49 ; 51 \%$ ), age ("a lot", $n=49$; $51 \%$ ), and "chemotherapy" ("a lot", $n=46 ; 47.9 \%$ ). Only for two items was the proportion of participants who reported "a lot" greater than 50\%. In contrast, more than half of participants reported having only "a little" knowledge about eleven items including all items in the Infertility Information subscale. Figure 1 presents boxplots for subscales and total scale scores. Subscales of which participants reported having the least knowledge were Alternative Parenting Options, and Infertility Information, while participants reported the most knowledge about General Information about Fertility. Participants reported overall knowledge of fertility and fertility 
Table 2 Descriptive statistics for the item responses, subscales, and total KF Scale $(n=96)$

\begin{tabular}{|c|c|c|c|c|c|c|c|c|c|}
\hline \multirow[t]{3}{*}{ KF subscale or item } & \multicolumn{9}{|c|}{ Item responses $(n=96)$} \\
\hline & \multicolumn{2}{|c|}{ A little } & \multicolumn{2}{|c|}{ Some } & \multicolumn{2}{|c|}{ A lot } & \multirow[t]{2}{*}{ Mean score (SD) } & \multicolumn{2}{|c|}{$\begin{array}{l}\text { Corrected } \\
\text { correlations }\end{array}$} \\
\hline & $\mathbf{n}$ & $\%$ & $\mathbf{n}$ & $\%$ & $\mathbf{n}$ & $\%$ & & Subscale & Total \\
\hline Normal Reproductive Function & & & & & & & $\mathrm{I} .76(0.6 \mathrm{I})$ & & \\
\hline Female reproductive cycle & 11 & 11.5 & $4 I$ & 42.7 & 44 & 45.8 & & 0.53 & 0.36 \\
\hline Follicular phase & 60 & 62.5 & 23 & 24.0 & 13 & 13.5 & & 0.82 & 0.60 \\
\hline Ovulatory phase & 44 & 45.8 & 29 & 30.2 & 23 & 24.0 & & 0.76 & 0.61 \\
\hline Luteal phase & 70 & 72.9 & 14 & 14.6 & 12 & 12.5 & & 0.66 & 0.55 \\
\hline General Information about Fertility & & & & & & & $2.1(0.56)$ & & \\
\hline Age & 10 & 10.4 & 37 & 38.5 & 49 & 51.0 & & 0.50 & 0.61 \\
\hline Obesity & 35 & 36.5 & 35 & 36.5 & 26 & 27.1 & & 0.57 & 0.39 \\
\hline Smoking & 23 & 24.0 & 24 & 25.0 & 49 & 51.0 & & 0.54 & 0.32 \\
\hline Chronic health problems & 36 & 37.5 & 43 & 44.8 & 17 & 17.7 & & 0.49 & 0.54 \\
\hline Treatment Factors Affecting Fertility & & & & & & & $1.96(0.60)$ & & \\
\hline Breast cancer & 20 & 20.8 & 41 & 42.7 & 35 & 36.5 & & 0.77 & 0.52 \\
\hline Chemotherapy & 18 & 18.8 & 32 & 33.3 & 46 & 47.9 & & 0.73 & 0.62 \\
\hline Radiation therapy & 49 & 51.0 & 33 & 34.4 & 14 & 14.6 & & 0.49 & 0.26 \\
\hline Hormonal therapy & 44 & 45.8 & 32 & 33.3 & 20 & 20.8 & & 0.49 & 0.56 \\
\hline Infertility Information & & & & & & & $1.48(0.49)$ & & \\
\hline Assisted reproductive technology & 53 & 55.2 & 29 & 30.2 & 14 & 14.6 & & 0.68 & 0.61 \\
\hline Egg, embryo, and sperm donation & 53 & 55.2 & 28 & 29.2 & 15 & 15.6 & & 0.73 & 0.55 \\
\hline Infertility workup & 67 & 69.8 & 19 & 19.8 & 10 & 10.4 & & 0.66 & 0.71 \\
\hline Psychosocial concerns & 66 & 68.8 & 24 & 25.0 & 6 & 6.3 & & 0.48 & 0.49 \\
\hline Child-free living & 66 & 68.8 & 19 & 19.8 & 11 & 11.5 & & 0.26 & 0.23 \\
\hline Online resources & 60 & 62.5 & 28 & 29.2 & 8 & 8.3 & & 0.59 & 0.66 \\
\hline Alternative Parenting Options & & & & & & & $1.56(0.55)$ & & \\
\hline Pregnancy and breast cancer & 37 & 38.5 & 42 & 43.8 & 17 & 17.7 & & 0.70 & 0.63 \\
\hline Children after cancer & 48 & 50.0 & 30 & 31.3 & 18 & 18.8 & & 0.73 & 0.63 \\
\hline Surrogacy and gestational carriers & 78 & 81.3 & 13 & 13.5 & 5 & 5.2 & & 0.45 & 0.54 \\
\hline Adoption & 60 & 62.5 & 21 & 21.9 & 15 & 15.6 & & 0.53 & 0.33 \\
\hline Total KF Scale & & & & & & & $\mathrm{I} .74(0.4 \mathrm{I})$ & & \\
\hline
\end{tabular}

Abbreviations: KF, Knowledge of Fertility; SD, standard deviation.

preservation between "a little" and "some" (mean = 1.74; $\mathrm{SD}=0.04)$.

Based upon criterion-related association tests, participants' total KF Scale scores were significantly associated with reported treatment status $\left(\mathrm{F}_{(2,93)}=3.18 ; P=0.0462\right)$. Participants who had finished treatment reported higher levels of knowledge $(n=46$, mean $=1.85$; $\mathrm{SD}=0.06)$, than participants who had not yet started treatment $(n=13$, mean $=1.68$; $\mathrm{SD}=0.11)$ or were currently undergoing treatment $(\mathrm{n}=37$, mean $=1.63 ; \mathrm{SD}=0.07)$. Participants' Infertility Information subscale scores were significantly associated with having had consultations with reproductive specialists $\left(\mathrm{F}_{(1,94)}=4.12\right.$; $P=0.0452$ ). Participants who reported consultations with reproductive specialists had higher levels of knowledge for this subscale $(\mathrm{n}=22$, mean $=1.66$; $\mathrm{SD}=0.10)$, than participants who did not report such consultations $(n=74$, mean $=1.42 ; \mathrm{SD}=0.06$ ). Participants' Alternative Parenting Options subscale scores were significantly associated with education $\left(\mathrm{F}_{(2,93)}=3.81 ; P=0.0258\right)$. Participants with graduate school education obtained higher subscale scores on average $(n=50$, mean $=1.70 ; S D=0.07)$, than participants who were either college graduates $(n=34$, mean $=1.43$; $\mathrm{SD}=0.09)$ or had not completed a college degree $(\mathrm{n}=12$, mean $=1.35 ; \mathrm{SD}=0.15$ ).

\section{Discussion}

The KF Scale is a new instrument designed to measure a breast cancer survivor's self-assessed level of knowledge of fertility and fertility preservation. The initial trial suggests that the KF Scale is reliable and easy to use. Findings from this study also provide valuable information about young survivors' self-assessed level of knowledge of fertility and fertility preservation in addition to providing insight into variation between groups of young cancer survivors.

Many participants self-assessed their overall knowledge of fertility and fertility preservation as "a little" and the majority rated their knowledge for the Infertility Information subscale as "a little". This indicates that many participants had initiated 


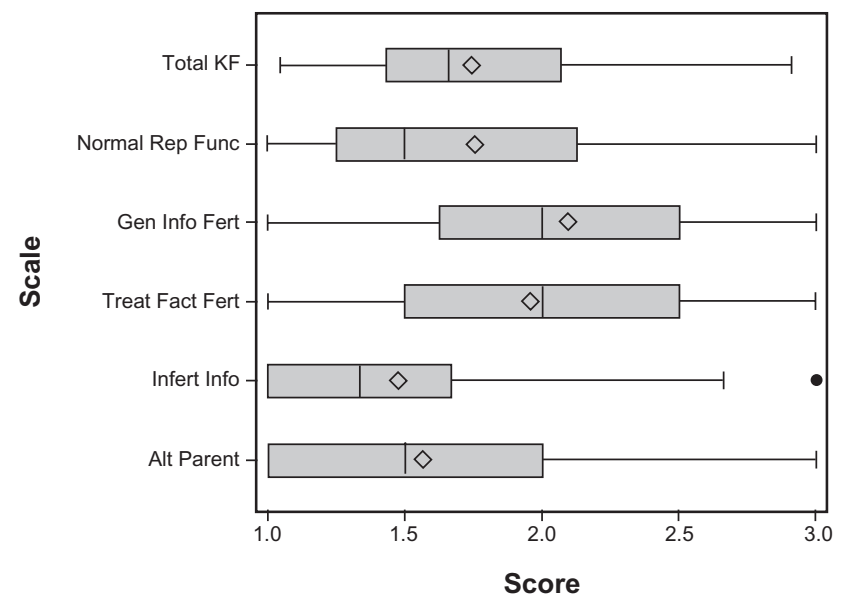

Figure I Boxplots for the total KF Scale and module subscales.

Note: Scores near I indicate that the responses tended to be "a little" knowledge, scores around 2 indicate that the responses tended to be "some" knowledge, and scores near 3 indicate that the responses tended to be "a lot" of knowledge $(n=96)$. Abbreviations: KF, Knowledge of Fertility.

or completed chemotherapy with little knowledge of the effect of breast cancer treatment on fertility and fertility preservation. Access to accurate and timely health information in regard to fertility and fertility preservation is critical prior to initiating treatment, as once chemotherapy has been initiated, the possibility of successful fertility preservation using traditional treatment methods is quite low. ${ }^{9}$ As comprehensive knowledge of fertility preservation (including possible treatments, benefits/ harms, and probable outcomes) is a prerequisite for women to fully participate in informed medical decision making on fertility preservation, ${ }^{9}$ these findings are of concern.

Interest in receiving accurate and specific health information is common across virtually all illnesses. ${ }^{22}$ However, cancer patients often report great variability in the volume of health information they receive ranging from "too much information" to "too little information". ${ }^{23,24}$ Health care professionals providing care for young women newly diagnosed with breast cancer must be able to provide needed health information on a wide range of topics (eg, surgery, chemotherapy, fertility preservation) in a relatively short period of time. The KF Scale could be used to develop individualized teaching plans to meet patient-identified fertility and fertility preservation health information needs. The KF Scale could also be used to examine the effectiveness of educational interventions if used before and after the intervention.

\section{Recommendations for future studies}

The Knowledge of Fertility (KF) scale performed well within this group of young breast cancer survivors.
However, additional research is needed to further determine the reliability and validity of this instrument. Repeated measurements with larger samples could be used to further examine the reliability of the KF Scale with young breast cancer survivors. Further validation of the KF Scale could be accomplished through examining the performance of the KF Scale within diverse populations of young breast cancer survivors (age, race, socioeconomic status).

The KF Scale could be used to measure self-assessed knowledge of fertility and fertility preservation across diverse groups of young cancer survivors, such as survivors of Hodgkin's disease. Further studies to examine the potential use of the KF Scale to measure parental knowledge of fertility and fertility preservation for adolescents and children diagnosed with cancer are needed. These studies would support the development of patient-centered health education interventions specific to meet the unique educational needs of survivors and cosurvivors.

It is possible that self-assessed knowledge is not correlated with actual level of knowledge. ${ }^{25}$ Research to examine use of the KF Scale in conjunction with an additional instrument to objectively assess knowledge of fertility and fertility preservation would provide insight into patient's ability to accurately self-assess knowledge. This would further validate the KF Scale and allow nurses to have a high level of confidence in the appropriateness of educational interventions based upon survivor self-assessed knowledge strengths and deficits.

The relatively small sample size and use of a convenience sample limits generalizability of the study findings. Further, the majority of the women participating in this study had above average income, above average levels of education, health insurance, and internet access. It is possible that women with lower income, lower levels of education, who are either un- or underinsured, and/or have limited internet access will have different levels of knowledge of fertility and fertility preservation than did women participating in this study. Additional research is needed to determine if differences in self-assessed knowledge varies among women from diverse socioeconomic backgrounds. Further, research to examine the quality, quantity, and timeliness of health information specific to fertility and fertility preservation and subsequent health outcomes for diverse groups of young breast cancer survivors is needed.

\section{Conclusion}

Infertility is a severe and often underestimated consequence of successful cancer treatment. ${ }^{10}$ Ensuring young breast 
cancer survivors receive patient-centered health information in a timely manner is a critical component of high quality nursing care. Until now, instrumentation to support young breast cancer survivor self-assessment of knowledge of fertility and fertility preservation has been unavailable. Preliminary results indicate that self-assessed knowledge of fertility and fertility preservation can be measured using the KF Scale. Additional research is needed to further determine the reliability and validity of the KF Scale in larger and more diverse groups of young cancer survivors.

\section{Disclosure}

The authors report no conflicts of interest in this work.

\section{References}

1. American Cancer Society. Breast cancer facts and figures 2009-2010. Available from: http://www.cancer.org/Research/CancerFactsFigures/ BreastCancerFactsFigures/f861009-final-9-08-09-pdf. Accessed on February 10, 2012.

2. Oktem O, Oktay K. Fertility preservation for breast cancer patients. Semin Reprod Med. 2009;27(6):486-492.

3. Canada AL, Schover LR. The psychosocial impact of interrupted childbearing in long-term female cancer survivors. Psychooncology. 2012;21(2):134-143.

4. Abusief ME, Missmer SA, Ginsburg ES, Weeks JC, Partridge AH. The effects of paclitaxel, dose density, and trastuzumab on treatment-related amenorrhea in premenopausal women with breast cancer. Cancer. 2010;116(4):791-798.

5. Swain SM, Land SR, Ritter MW, et al. Amenorrhea in premenopausal women on the doxorubicin-and-cyclophosphamide-followed-bydocetaxel arm of NSABP B-30 trial. Breast Cancer Res Treat. 2009;113(2): 315-320.

6. Schover LR. Psychosocial aspects of infertility and decisions about reproduction in young cancer survivors: a review. Med Pediatr Oncol. 1999;33(1):53-59.

7. Domar AD, Zuttermeister PC, Friedman R. The psychological impact of infertility: a comparison with patients with other medical conditions. J Psychosom Obstet Gynaecol. 1993;14 Suppl:45-52.

8. Murray RS. Fertility sparing options for breast cancer patients. Breast Dis. 2005-2006;23:73-80.

9. Hulvat MC, Jeruss JS. Maintaining fertility in young women with breast cancer. Curr Treat Options Oncol. 2009;10(5-6):308-317.
10. Tomao F, Spinelli GP, Panici PB, Frati L, Tomao S. Ovarian function, reproduction and strategies for fertility preservation after breast cancer. Crit Rev Oncol Hematol. 2010;76(1):1-12.

11. Canada AL, Schover LR. Research promoting better patient education on reproductive health after cancer. $J$ Natl Cancer Inst Monogr. 2005;34:98-100.

12. Zebrack BJ, Casillas J, Nohr L, Adams H, Zeltzer LK. Fertility issues for young adult survivors of childhood cancer. Psychooncology. 2004;13(10):689-699.

13. Schover LR, Rybicki LA, Martin BA, Bringelsen KA. Having children after cancer. A pilot survey of survivors' attitudes and experiences. Cancer. 1999;86(4):697-709.

14. Meneses K, McNees P, Azuero A, Jukkala A. Development of the Fertility and Cancer Project: an Internet approach to help young cancer survivors. Oncol Nurs Forum. 2010;37(2):191-197.

15. Meneses K, McNees P, Azuero A, Jukkala A. Evaluation of the Fertility and Cancer Project (FCP) among young breast cancer survivors. Psychooncology. 2010;19(10):1112-1115.

16. Polit DF, Beck CT. Nursing Research: Generating and Assessing Evidence for Nursing Practice. 8th ed. Philadelphia, PA: Lippincott Williams and Wilkins; 2008.

17. Institute of Medicine Committee on Quality of Health Care in America. Crossing the Quality Chasm: A new Health System for the 21st Century. Washington, DC: National Academy Press; 2001.

18. Brixey MJ, Mahon SM. A self-assessment tool for oncology nurses: preliminary implementation and evaluation. Clin J Oncol Nurs. 2010;14(4):474-480.

19. Rennie H, Mackenzie G. The psychosocial oncology learning assessment: a province-wide survey of cancer care providers' learning needs $J$ Cancer Educ. 2010;25(2):206-210.

20. Jones JM, James J, Rodin G, Catton P. A province-wide needs assessment of oncology health care professionals in psychosocial oncology. J Cancer Educ. 2001;16(4):209-214.

21. Susan G. Komen for the Cure. Komen news: Highlights from the 2004 Mission Conference: Pathways to a promise. Available from: http://ww5.komen.org/KomenNewsArticle.aspx?id=7884. Accessed March 3, 2012.

22. Sepucha K, Mulley AG Jr. A perspective on the patient's role in treatment decisions. Med Care Res Rev. 2009;66 Suppl 1:53S-74S.

23. Mann KS. Education and health promotion for new patients with cancer. Clin J Oncol Nurs. 2011;15(1):55-61.

24. Wong JJ, D'Alimonte L, Angus J, Paszat L, Soren B, Szumacher E. What do older patients with early breast cancer want to know while undergoing adjuvant radiotherapy? J Cancer Educ. 2011;26(2):254-261.

25. Crosby RA, Yarber WL. Perceived versus actual knowledge about correct condom use among US adolescents: results from a national study J Adolesc Health. 2001;28(5):415-420.
Nursing: Research and Reviews

\section{Publish your work in this journal}

Nursing: Research and Reviews is an international, peer-reviewed, open access journal publishing original research, reports, reviews and commentaries on all aspects of nursing and patient care. These include patient education and counselling, ethics, management and organizational issues, diagnostics and prescribing, economics and

\section{Dovepress}

resource management, health outcomes, and improving patient safety in all settings. The manuscript management system is completely online and includes a very quick and fair peer-review system. Visit http://www.dovepress.com/testimonials.php to read real quotes from published authors. 